Fecha de recepción: diciembre 2018 Fecha de aceptación: marzo 2019 Versión final: abril 2019

\section{La innovación en la creación y comercialización de animales fantásticos en Arrazola, Oaxaca}

Yésica A. del Moral Zamudio *

Resumen: La necesidad económica combinada con la cercanía a uno de los centros arqueológicos más importantes del estado de Oaxaca hizo que los hombres de la población de Arrazola repararan en la existencia de la demanda de productos innovadores. Ello los llevó a desarrollar una tradición artesanal que ha florecido por los últimos ochenta años. Tanto la creación como la comercialización de las piezas talladas en madera de copal elaboradas en Arrazola ha llevado a los artesanos a generar procesos innovadores que se han ido transformando a través del tiempo acorde a la necesidad.

A partir del aprendizaje autodidacta de la técnica de tallado, la evolución de las formas de cada artesano se desarrolló por años de manera aislada y totalmente secreta en talleres familiares ubicados en las casas de sus creadores lográndose una clara definición de estilos propios que se conservan hasta la fecha, pero las constantes crisis políticas y económicas los forzaron recientemente a salir de ese aislamiento para formar organizaciones civiles temáticas cuyo objetivo es promover en conjunto las piezas de todos sus integrantes.

La peculiaridad de las creaciones de Arrazola es que nominalmente corresponden a animales conocidos pero formal, cromática y compositivamente presentan la propuesta de una nueva realidad existente sólo en la fantasía de sus creadores quienes los visualizan de manera previa al tallado a través de su poder imaginativo y los materializan mediante el uso de madera, un machete, cuchillos caseros y pintura acrílica. Los talladores se definen a sí mismos como artesanos y aunque algunos de ellos se sienten poseedores del arte como un don natural ligado a la inspiración divina, en su mayoría describen el proceso creativo como una compleja combinación de planeación mental enriquecida por la observación, la experimentación y el esfuerzo constante siempre dirigido hacia la búsqueda de innovación.

Palabras clave: imaginación - creatividad - innovación - proceso creativo

[Resúmenes en inglés y portugués en las páginas 88 - 89]

${ }^{(*)}$ Doctora en Artes Visuales por la Universidad Politécnica de Valencia se ha desempeñado como docente y comunicadora gráfica en instituciones gubernamentales y privadas en México. Actualmente coordina la Licenciatura en Gestión y Desarrollo de las Artes en la Universidad La Salle Oaxaca. 


\section{Introducción}

El presente artículo expondrá el proceso creativo de los artesanos de una pequeña población del estado mexicano de Oaxaca llamada Arrazola. San Antonio Arrazola se encuentra localizado en la región de los Valles Centrales de Oaxaca, estado del suroeste mexicano que cuenta con una gran diversidad cultural y tradición artesanal. Arrazola pertenece al distrito del Centro, formando parte del municipio de Santa Cruz Xoxocotlán y se conecta con la ciudad de Oaxaca a través de la carretera Oaxaca-Zaachila mediante taxis, colectivos y vehículos privados.

El territorio que conforma Arrazola fue parte de una de las treinta y un haciendas localizadas en esa área. Dedicada al procesamiento del azúcar fue propiedad de Pedro Larrañaga quien en 1929 cedió su tierra a los peones para que fundaran el pueblo en honor a San Antonio. Los primeros moradores completaron el nombre del lugar con el apellido de la esposa del hacendado, Luisa Arrazola.

Actualmente Arrazola cuenta con una iglesia, una oficina de ayuda ejidal, una agencia municipal, una clínica de salud, una plaza, un kínder, una escuela primaria, canchas de vóleibol, básquetbol, futbol soccer y pelota mixteca, deporte derivado del juego de pelota prehispánico que goza de gran popularidad en la zona. Arrazola continúa siendo un poblado campesino de alrededor de dos mil habitantes, de acuerdo a los cálculos de sus propios habitantes (Morales, Susano. Entrevista personal, 2019).

Se encuentra ubicado a los pies del extremo sur del cerro de Monte Albán, donde se asienta uno de los principales centros arqueológicos de la cultura zapoteca, al que asiste un número considerable de turistas nacionales y extranjeros a lo largo de todo el año.

Aunque Arrazola no está constituido por población indígena, cuenta con la influencia y herencia de costumbres de ese origen como la reciprocidad en el trabajo comunal, la ayuda familiar y las mayordomías, sistema social a través del cual se elige, de manera anual, un encargado o padrino que tendrá a su cargo la fiesta religiosa vinculada con imágenes o esculturas devocionales de santos de la tradición católica.

Las casas normalmente cercadas con carrizos se hallan rodeadas por vegetación y están siempre abiertas al libre tránsito de vecinos, familiares, turistas, gallinas y perros. En ellas se ubica un lugar para el tallado y pintado de las piezas, el patio central para el secado y uno de los cuartos para colocar los trabajos terminados en exposición para la venta.

Los datos del presente artículo surgieron mediante una recopilación realizada con los métodos de investigación de campo de historia oral y observación no participante. Dicho trabajo se realizó de manera intensiva a lo largo de un año en el 2000 y más tarde en visitas esporádicas a lo largo de diecinueve años hasta el presente. Durante el trabajo de campo se llevaron a cabo continuas entrevistas personales con siete artesanos del lugar en las que se recabó la descripción conceptual de su propio proceso de creación a la vez que se observaba la manera en que llevaban a cabo el tallado.

Una vez recopiladas las distintas versiones del proceso creativo fueron organizadas en teorías intuitivas o naturales, entendidas como lo surgido de la sinceridad directa, lo natural o espontáneo, para identificar rasgos comunes. Para describir la capacidad innovadora de los artesanos se presentarán referencias contextuales desde una perspectiva interdisci- 
plinaria a partir de la filosofía, la psicología y la antropología que ayuden a establecer un marco teórico en torno a características individuales del conocimiento tales como imaginación e inteligencia. El aspecto social del proceso creativo se abordará desde el concepto de creatividad entendido como interacción de sistemas. A lo largo del desarrollo del artículo también se describirá la transformación del acercamiento a la comercialización en respuesta a las distintas crisis sociales y económicas del estado.

\section{Epistemología del proceso creativo}

Para los fines del presente artículo se entenderá por imaginación una función productora de formas figurativas representativas de los objetos. Es decir, se la asume como la capacidad de crear imágenes desde la teoría filosófica de la imaginación de María Noel Lapoujade (1998). Asimismo se concibe por inteligencia la forma de realizar, suscitar y dirigir operaciones mentales capaces de conocer la realidad, guiar el comportamiento, inventar posibilidades, crear y manejar irrealidades implicando la adaptación al medio y, por lo tanto, su interpretación y cambio a partir de la teoría de la inteligencia creadora de José Antonio Marina (1993) y Jacob Bronowski (1979). Desde dichas perspectivas se puede decir que, tanto la imaginación como la inteligencia están presentes en los procesos epistémicos que el sujeto despliega para comprender y crear.

Las actividades cognitivas de percepción, memoria, entendimiento y razón tienen también una importancia determinante en el proceso creativo debido a que, desde el momento mismo que se entra en contacto con un objeto sensorial, se llevan a cabo acciones de interpretación y discriminación que determinan la experiencia de la realidad, su conocimiento y por lo tanto su transformación. En este sentido, Lapoujade (1998) considera que la imaginación realiza actividades de síntesis, complementación y desbordamiento en la percepción, construyendo, afirmando y proponiendo sobre la negación y transgresión que son los dínamos de su actividad.

Otros aspectos de la imaginación que son relevantes al tema consisten en la habilidad para sintetizar la diversidad perceptual reduciéndola a una sola imagen, con lo cual se facilita el entendimiento, y su contribución a la generación de conceptos e imágenes que traducen configurativamente objetos insertando su representación de acuerdo a categorías para lograr reconocimiento (Lapoujade, 1998). Además de ello, las imágenes creadas a través de la imaginación también pueden alterar el precepto, ya sea completándolo, corrigiéndolo, distorsionándolo o inclusive falseándolo.

La síntesis es la actividad unificadora y mediadora de la imaginación, la cual permite dar identidad a los objetos y forma en imagen a las actividades abstractas de reflexión y simbolización generando así conocimiento. A su vez, dicha generación de conocimiento puede ejercer una función de construcción teórica de anticipaciones que pueden ser lógicas, reales o del todo innovadoras y generadoras de su propio orden, tal como ocurre en la creación de mundos fantásticos. En ese sentido, la imaginación desde el planteamiento filosófico, es fuente originaria del conocimiento, descubrimiento, invención y creación. 
La inteligencia, por su parte, interviene en la percepción al dar significado a la recepción de estímulos mediante la identificación y el reconocimiento; pero también interviene en la creación de nuevas construcciones perceptivas al reorganizar las operaciones mentales para integrarlas en proyectos autodeterminados por el creador (Bronowski, 1979).

El tercer concepto que es comúnmente utilizado para estudiar del proceso creativo es la creatividad. El acercamiento propuesto en este artículo no retoma su concepción de aptitud, centrada únicamente en la actividad y producción del individuo (Tatarkiewicz, 1997) sino en una aproximación social en la cual se le considera un proceso, el modelo de sistemas planteado por Mihaly Csikszentmihalyi y Howard Gardner donde interactúan tres elementos: una cultura o conocimiento simbólico compartido por una sociedad particular que contiene reglas y procedimientos simbólicos denominado campo, un ámbito de expertos que reconocen, promueven y validan la innovación y finalmente un individuo que aporta novedad al campo simbólico (Csikszentmihalyi, 1996 y Gardner, 1995).

En el caso específico de Arrazola, el análisis a la luz de estos tres conceptos expuestos: imaginación, inteligencia y creatividad de las producciones artesanales y de su interacción resulta contundente.

\section{Consideraciones históricas en torno a la innovación}

El último concepto que forma parte de la base conceptual de la discusión del presente artículo está también ligado a la creatividad y es la innovación. Esta categoría conceptual se abordará a partir de la diferencia entre imitar y crear.

La imitación (mímesis) ha sido planteada históricamente en torno a la expresión de una realidad interior, al funcionamiento de la naturaleza y a la copia de la apariencia de las cosas, visión que encontró en Platón y Aristóteles dos vertientes (Tatarkiewicz, 1977). Para el primero, la imitación era la copia fidedigna de la realidad, mientras que para el segundo era una libre creación basada en los elementos de la naturaleza que implicaba el desarrollo de un enfoque personal relativo a la forma de representación del artista. Estos planteamientos generaron variantes respecto a imitar lo visible o lo invisible. Por ejemplo Plotino escribió en su Eneada V que "las artes no imitan simplemente las cosas visibles, sino que llegan hasta los principios que constituyen el origen de la naturaleza" (Plotino, Enéada V, $8,1,1955)$ haciendo una referencia a las leyes a partir de las cuales se producen las cosas. Por otro lado, Platón en La República, describe al artista como forjador de ilusiones en el sentido de un fabricante de simulacros, cuando el artista crea una "apariencia ilusoria" en lugar de una simulación del objeto, es decir, "una imitación de aquello de que otros son artífices" (Platón, 1959, Libro X). El mencionado autor, llega incluso al extremo de considerar el arte no sólo como una copia fidedigna del mundo exterior sino como una copia pasiva.

La disputa de los escritores del Renacimiento y Barroco en torno a si la imitación es tarea demasiado difícil, basada en el planteamiento de que la imitación no puede igualar nunca al modelo, o si, por el contrario, es demasiado insignificante y pasiva para el arte (Tatarkiewicz, 1977) es prolífica. Más aún, el cuestionamiento sobre su exactitud o fidelidad 
llevó a la posibilidad de no buscar la copia escrupulosa sino la creación a un nivel ilusorio o representacional, para hacer más bella la naturaleza, tal como expresa Miguel Ángel en su Le lettere de 1550, o bien para hacer algo incluso más perfecto que el objeto imitado (Danti, 1567, II).

En dicho nivel, es incluso posible manifestar un mundo ideal distinto del real que es propio del autor que imita. Desde esa perspectiva, una pregunta filosófica llama la atención con respecto a si en verdad el hombre puede hacer algo nuevo, algo que no haya existido antes a partir de sí mismo, de sus conocimientos o experiencias, a través de guiar el conjunto de sus facultades mentales para reproducir, a partir de su interior, la vida en una combinación nueva. Lo cual remite nuevamente a la teoría de la inteligencia creadora ya mencionada.

Otra manera de generar algo original de acuerdo a autores como Herbert Read es ir a la naturaleza o a los objetos para conocer su origen, y transponerlo en algún material concreto, cambiando su significado para comunicar algo que no se ha dicho antes, a través de revelar por primera vez alguno de sus aspectos (Read, 1965). Ello refiere a originalidad el sentido de la palabra originalis, algo que es propio de su creador no siendo la copia o reproducción de alguien más y surge a través del trabajo consciente que involucra la sensibilidad, capacidad de observación y síntesis del autor, lo cual también aplica a la actividad creadora del trabajo de los talladores de Arrazola.

\section{Los talladores de Arrazola}

Los hombres de Arrazola habían sido históricamente campesinos que trabajaban la tierra cultivando maíz, frijol, calabaza, semillas de temporada y pasturas para alimento del ganado, y se ayudaban de actividades como la albañilería o la plomería para completar el ingreso familiar. Pero su cercanía a la zona arqueológica de Montealbán los hizo curiosos a la presencia extranjera y algunos de ellos buscaron a través del tiempo diferentes objetos que pudieran ser vendidos a los visitantes. Los objetos abarcaban una amplia gama, desde piezas arqueológicas originales encontradas en las laderas del cerro hasta pequeños recuerdos y artesanías.

Hace unos ochenta años, algunos hombres del lugar empezaron a tallar animales en la madera de los árboles de copal endémicos de la zona, inspirados en la tradición de usar máscaras para el Día de Muertos elaboradas con el mismo material y tuvieron tal éxito que comenzaron a atraer a los turistas al pueblo. El incremento en la demanda generada por un grupo de extranjeros, en especial norteamericanos, conformaron el ámbito que incitó a otros pobladores a aprender por cuenta propia el tallado de la madera.

Conforme más y más habitantes se dedicaron a esta actividad, aumentó también la competencia y con ello mejoró la calidad del trabajo puesto que los compradores, teniendo tanta variedad de elección, empezaron a escoger las piezas con mayor cuidado, lo cual obligó a los artesanos a rendir más y con llegó la especialización.

Las figuras surgieron del dominio de la técnica y métodos de trabajo propios de cada artesano desarrollados experimentalmente a lo largo de un par de décadas, de su cultura 
visual general producto del contexto social local y ante todo de la particular selección y combinación de elementos que hicieron para generar formas propias con las cuales enfrentar la competencia. Es por ello que los artesanos se refieren a su trabajo diciendo, por ejemplo: "esta es la forma en la que nosotros hacemos las iguanas" (Morales, Susano. Entrevista personal, 2000).

Es mediante la expresión antes citada que los artesanos se refieren al hecho de que esa figura no es la representación exacta de ese tipo de animal sino que corresponde a una elección consciente de fragmentos de la forma natural que son estilizados a través de su poder imaginativo para concebir algo nuevo. Un importante factor contribuyente al desarrollo de formas especializadas fue la implementación de un sistema de trabajo familiar que, por muchos años, se mantuvo en estricto secreto del resto de los pobladores.

El desconocimiento del trabajo de unos artesanos con respecto al trabajo de sus vecinos fue narrado por los artesanos en referencia a los primeros años del florecimiento de esta actividad en el pueblo. Parte de las anécdotas contadas acerca de esos años incluyen hechos tales que merecerían ser parte de una novela de espionaje. Este desconocimiento de la labor entre ellos surgió también cuando la autora del artículo les mostraba algunas de las fotografías, siendo este acercamiento fotográfico, para muchos, el primer vislumbre del trabajo de los demás.

Además del consenso constante que ocurre al interior de la familia, los artesanos observan con atención los gustos de los clientes, entendiendo este concepto desde el planteamiento de Pierre Bourdieu (2010) como la capacidad de diferenciar y enunciar una preferencia, y en tal sentido la distinción, y a partir de ello favorecer o descartar el uso de unas formas y colores por sobre otras. De esa manera, el gusto de los compradores se convierte en referente de selección, combinación formal y cromática de los artesanos para desarrollar un trabajo que se liga al folklore mexicano. Se entiende el concepto de folklore siguiendo la raíz de la palabra, en tanto conocimiento del pueblo, o expresión artística que revela la psicología de la sociedad a la que pertenece y de este modo también refleja su moral y costumbres (Martínez, 1980).

Sin embargo, la realidad encontrada en la observación de campo muestra que los artesanos no llevan a cabo dicha selección a partir de sí mismos y sus propios gustos o preferencias sino buscando agradar a un comprador que demanda como satisfactor y requisito de venta una idea preconcebida de la artesanía mexicana. Dicha idea prefijada de lo artesanal y lo mexicano, está ligada al sentido de identidad nacional que fue promovido a partir de la segunda mitad del siglo XIX, al cobijo del romanticismo, por la élite intelectual del momento y algunos empresarios y comerciantes extranjeros (Ovando, 2008).

Una vez que cada artesano tuvo una técnica desarrollada y con formas altamente definidas tuvo inicio la primera iniciativa de agrupamiento del pueblo en una asociación civil registrada para, en sus propias palabras, "tener mayor peso y ser más escuchados" (Santiago, Miguel. Entrevista personal). En ese grupo que reunía treinta artesanos, se buscaba resolver problemas comunes como la deforestación del cerro por la explotación excesiva de la madera de copal usada para el tallado. No obstante en cuanto a la producción, aún mantenían sus piezas para sí mismos. 
Quince años después de haber realizado aquel primer año de prácticas de campo, al regresar al pueblo en el 2015, los vecinos estaban celebrando una feria artesanal donde cada familia contaba con una mesa en la que mostraba sus piezas de manera totalmente pública a los demás. De este modo, las artesanías mutaron su estatus y comenzaron a ser públicas en el ámbito de su venta y socialización. Asimismo, para entonces ya habían formado numerosas asociaciones civiles temáticas que trabajan en conjunto para la promoción de las figuras de todos sus integrantes como la Asociación de Mujeres Creativas de Sueños en Madera y Pintura, constituida ante el Instituto Oaxaqueño de las Artesanías, e integrada por diecinueve mujeres que representan el mismo número de familias de talladores.

Sin embargo, también existen familias, especialmente las de los descendientes de los pioneros de esta actividad en Arrazola, que se reservan la participación en ferias y asociaciones manteniéndose aislados en sus casas donde no les falta el trabajo por su ya logrado renombre internacional, incluso una de ellas está promoviendo este año de 2019 obtener la certificación de origen para las figuras talladas en el pueblo.

\section{Los animales fantásticos de Arrazola}

Cuando alguien escucha animales fantásticos mexicanos en relación a artesanía, inmediatamente piensa en alebrijes. Según su propio creador, Pedro Linares, éstos son seres fantásticos que uno ha creado de su memoria, que uno ha visto o está viendo. Él mismo solía decir que los alebrijes eran la expresión material de visiones que tuvo en los años cincuenta al padecer de fuertes fiebres. Tal como sostiene Linares en una entrevista: "pensé que me iba a morir, pero tuve un sueño y en una revelación vi esos animales... pero realmente cosas feas. Por eso yo creo que reviví de nuevo, regresé de la muerte e hice lo que vi en el otro lado. Eso es lo que he perfeccionado." (Masuoka, 1994, p. 99)

Los alebrijes se desarrollaron a partir de la tradición de los Judas de papel maché y en sus inicios estaban conformados por la combinación de cabezas de distintos animales colocadas en cuerpos humanos. Con el tiempo se cambió la forma del cuerpo eliminando las referencias a la posición humana erecta, se les dotó de expresivos gestos y movimientos y se empezó a trabajar en su decoración hasta lograr piezas con reconocimiento mundial ligadas a México.

Actualmente por alebrijes se entienden a los seres creados con partes de distintos animales hechos en papel maché y su popularidad es tal que el Museo de Arte Popular de la Ciudad de México organiza cada año un desfile de alebrijes monumentales en torno a la celebración del Día de Muertos en la que participan cientos de organizaciones y colectivos de todo el país. La diferencia con los animales de Arrazola, aunque también llegan a llamarse alebrijes, es que sus formas normalmente corresponden a animales conocidos, sin mezclas de partes, pero en la mayoría de los casos presentan de manera formal, cromática y compositiva la propuesta de una nueva realidad. Además de ello su elaboración se lleva a cabo en madera. De acuerdo a María Noel Lapoujade "la fantasía, en general, es la operación de las funciones psíquicas por la que se crean imágenes que ni reproducen ni reconstruyen la realidad, sino que la alteran, en sentido literal, crean otra realidad" (1988, p. 136) y desde esa pers- 
pectiva los animales de Arrazola se convierten en fantásticos desde el momento que no buscan reproducir la realidad.

Sólo uno de los artesanos cuenta con una enciclopedia de animales porque está convencido que el estudio de los animales, de una u otra manera, le da sentido al trabajo. En sus libros aprende hacia qué lado flexionan las patas ciertas especies en comparación con otras y las variedades entre los animales, por ello es el único artesano que crea animales como guepardos o leones marinos.

El resto de los artesanos tienen normalmente sólo una idea vaga de la forma real de jirafas, jaguares, venados, iguanas y otros animales que constituyen parte del repertorio de animales a partir de los que crean, dado que no son seres con los que conviven regularmente. No obstante el acceso a internet está cambiando rápidamente su capacidad de búsqueda y ello se nota en las nuevas generaciones. Cabe aclarar que el interés de los talladores no ha sido tradicionalmente ver físicamente a los animales que hacen, sino concebirlos a través de la imaginación y desde ahí determinar el movimiento de sus patas, las formas de sus rasgos, la presencia o no de pelo.

Una vez terminado el trabajo de tallado se complementa la labor artesanal con aplicaciones ornamentales en color trabajadas en capas sobrepuestas que son inspiradas tanto en elementos de la naturaleza como en sus sueños. De allí que, según registros de campo con respecto a los motivos un artesano haya expresado: "los motivos para pintar las figuras se hallan por todas partes, sólo hay que observar" (Santiago, Miguel. Entrevista personal, 2000). En efecto, los artesanos refieren salir a caminar para fijarse en la forma de las hojas de las plantas, en los pistilos de las flores o en las gotas de lluvia que utilizan como motivos de decoración de las figuras (Morales, Francisco. Entrevista personal, 2000).

\section{La creación de las figuras}

La distribución del trabajo en Arrazola varía en relación con la destreza e interés de cada miembro de la familia. En general, los hombres son quienes realizan el tallado de la madera porque es un trabajo que requiere de mucha fuerza física y que puede ser peligroso. En efecto, durante esta actividad es fácil cortarse, según atestiguan las múltiples cicatrices que los artesanos tienen en las manos. Por su parte las mujeres tienden a estar encargadas del lijado y de la pintura de las piezas.

El trabajo de tallado se inicia normalmente con un machete para dar la forma general y según se avanza se cambia a cuchillos de cocina para hacer los detalles. Para quitar la madera se excava en forma de cuña, alternando de un lado a otro hasta conseguir la profundidad deseada para la parte más honda. A partir de ahí se modula el resto de la curva con los cuchillos que, por el trabajo de tallado y la constante afilada, van desgastándose hasta curvarse. Cuando la curva ha angostado la hoja en su totalidad, se corta y el cuchillo queda más pequeño aprovechándose para los detalles finos.

Normalmente se talla de una sola pieza de madera el cuerpo principal del animal, incluyendo cabeza, cuello y tronco, mientras que las orejas, alas, antenas, cola y patas se tallan por separado y se unen después. El cuerpo se talla de manera simultánea hasta lograr la 
forma básica y después se van enfocando en ciertas zonas, donde "se va observando de frente constantemente para que queden parejos todos los rasgos, no más angosto uno que otro o no más ancho" (Morales, Susano. Entrevista personal, 2000).

La comparación entre las partes y con el todo es constante para cuidar proporción, forma y movimiento. Para formas pares como las patas, se elige un tronco y se parte a la mitad para cada una de las piezas. En los detalles finos llevan a cabo el tallado de manera más lenta.

Un rasgo relevante del proceso es que la mayor parte del trabajo se realiza sin ningún trazo, sólo en detalles específicos como los ojos del animal llega a dibujarse el contorno. No obstante, en general, la figura se produce en la mente, como imagen, de manera previa al tallado y se traduce a la madera mediante un proceso de observación, comparación, validación y corrección constante. Es por ello que el tipo de figuras, sus proporciones, semejanza con la realidad y decoración cambia de familia a familia repitiéndose en ciclos inexactos. A pesar de ello, y debido a que las características particulares de la madera determinan muchos aspectos de las piezas como su dinamismo y tamaño, cada figura es en realidad única.

Los artesanos de Arrazola refieren a la imaginación como fuente de creación, sin embargo, engloban en este concepto concepciones diferentes de fondo. Una primera explicación compartida por varios talladores es que "las formas vienen de uno, de lo que es de uno" (Hernández, Evaristo. Entrevista personal, 2000). Ello implica talento o aptitud innata, pero no se plantea como algo dado sin justificación alguna. En efecto, para don Manuel Jiménez, el pionero de esta actividad en Arrazola, esta cualidad viene de un contacto divino previo al proceso creativo a través del cual existe una consagración del trabajo que le permite hacer figuras con espíritu. En su visión, desde la religión católica que practica, él adquiere la autorización divina a través de la oración y el buen comportamiento. En sus propias palabras:

“Tal vez la querencia de una mixteca con un zapoteco, mis padres, hizo de mí lo que soy; predicador, artesano. El arte lo traigo desde nacencia se puede decir, el oficio de tallador me lo enseñaron mis dioses" (Jiménez, Manuel. Entrevista personal, 2000).

Para don Miguel Santiago, además del talento natural, el trabajo de tallado implica una búsqueda de sentido, por lo que requiere de mucho estudio e investigación para lograr algo diferente. La familia Hernández presenta esta aptitud como producto de una evolución lograda mediante la dedicación del máximo esfuerzo al trabajo.

La segunda explicación encontrada en Arrazola es que "las formas surgen de lo que viene a la mente" (Morales, Francisco. Entrevista personal, 2000) y aunque es posible interpretarla como un tipo de creación espontánea, o el encuentro de inspiración en el sentido de algo que llega o aparece en la mente, se refiere en realidad a lo opuesto. En este sentido es un proceso de planeación mental donde las imágenes que serán llevadas a la madera se configuran previamente, ésta es la teoría sustentada por la mayoría de los artesanos, como don Francisco Morales o don Susano Morales y más importante aún, parece ser la manera en que trabaja la mayoría de los talladores.

La tercera explicación es que "las formas son lo que surge de la madera" (Morales, Francisco. Entrevista personal, 2000), ello implica desde el liberar formas que se encuentran presas dentro de una rama hasta los cambios que ocurren durante el proceso del tallado 
determinados por la estructura básica de la madera e implican alteraciones a la idea mental original que se tenía cuando se empezó a trabajar, éste es también un elemento reconocido por la mayoría de los artesanos.

Aunque estas teorías se presentan de manera separada para fines explicativos, en la práctica se combinan continuamente. Como puede verse, las descripciones de los talladores encuentran equivalente en los conceptos planteados dentro del marco conceptual al inicio del artículo. Esto es, la capacidad de crear imágenes, de configurar o dar forma usada se inscribe en el ámbito de la imaginación, presente en el quehacer de los artesanos, a través de la función mental de síntesis de la diversidad perceptual. Dicha percepción se completa, corrige, distorsiona o falsea a través de volver a ver o recordar imaginativamente lo visto. También es cierto que las formas se configuran mediante la experiencia personal o el conocimiento de lo que les es propio y de su entorno, a través de un ejercicio mental, en el cual en ocasiones tratan de convertirse en el animal para saber cómo es, cómo se mueve y expresarlo a partir de su esencia. Algunos de los artesanos incluso se relacionan con los animales como si estuvieran vivos, por ejemplo en una de las visitas, y en alusión a una jirafa que acababan de terminar un artesano expresó "qué bueno que viniste hoy a verla porque mañana se va a ir corriendo" (Hernández, Evaristo. Entrevista personal. 2000).

Finalmente el concepto de inteligencia como dirección de las operaciones mentales que lleva a conocer, interpretar y transformar el medio encuentra eco en la descripción de los talladores cuando refieren su trabajo como una actividad consciente que puede desarrollarse a través de esfuerzo y determinación individual.

\section{Conclusiones}

Es posible concluir que el punto de partida de la producción de animales fantásticos tallados en madera realizada por los artesanos de Arrazola no se encontró en el impulso creativo o la autoexpresión subjetiva de los artesanos. Antes bien dicha creación radica en su necesidad económica y, con el paso del tiempo, ello derivó en desarrollar y adecuar tareas y características específicas de la producción artesanal de acuerdo con las solicitudes encomendadas por clientes.

El hecho de que su trabajo surgiera como respuesta a una necesidad económica de sobrevivencia, estableció, desde el inicio, determinantes a su trabajo. En efecto, los artesanos se vieron obligados a desarrollar representaciones que tuvieran valor a partir de la concepción misma de la forma, para cumplir con la función de satisfacer el gusto o preferencias de los posibles compradores. Además de ello, el proceso de comercialización de las piezas ha hecho que los artesanos se enfrenten a la necesidad de superar la competencia surgida en el mismo poblado y ello lo han logrado a través de generar elementos representativos propios de cada familia en los que se especializaron con el paso del tiempo. De esa manera, su trabajo artesanal corresponde al planteamiento de la creatividad como modelo de sistemas, un proceso social de interacción de elementos que van más allá del individuo. Los artesanos refieren la originalidad en su trabajo como el resultado de un proceso co- 
tidiano a través del cual subordinan mirada, percepción, memoria y demás facultades cognitivas a la transformación e interpretación de los datos y señales de la realidad para la configuración mental o imaginación de formas que se determinan de manera previa al tallado. Ello corresponde a las explicaciones psicológicas y filosóficas del proceso creativo en torno a la inteligencia y a la imaginación.

Los artesanos explican, de manera intuitiva, que la intención de crear o la búsqueda de motivos es lo que conduce al individuo a ver, desde otra perspectiva. Esto es, en otras palabras, procurar inventar posibilidades creativas y ellos aseguran que la intención o autoderminación de crear algo innovador es lo que conduce al individuo a ver desde el significado, a inventar posibilidades perceptivas desde estímulos externos partiendo de la mirada para crear algo diferente. Por ello, aunque los artesanos se han visto indudablemente influenciados y determinados por el ámbito de sus compradores, quienes definen con su selección de piezas lo que permanece y lo que no se repite, sus creaciones resultan en algo original, algo que les es propio, a través del trabajo y la dedicación constante.

Las teorías intuitivas de los artesanos de Arrazola postulan la creación como una actividad compleja pero accesible al ser humano que presenta distintos grados de dificultad relativos a la conceptualización y elaboración física de la obra. Esta creación abarca un amplio rango de conocimientos que atañen al individuo pero no se puede ignorar la participación de los distintos factores económicos, sociales y culturales que históricamente han contribuido a determinar el proceso mismo de elaboración de los animales fantásticos de este poblado.

\section{Lista de Referencias bibliográficas}

Arnheim, R. (1979). Arte y percepción visual. España: Alianza Editorial. Bounarotti, M. (1550). Le lettere. Milanesi.

Bourdieu, P. (2010). El sentido social del gusto. Argentina: Siglo XXI

Bronowski, J. (1979). Los orígenes del conocimiento y la imaginación. Barcelona: Editorial Gedisa.

Csikszentmihalyi, M. (1996). Creatividad. España: Editorial Paidós Transiciones.

Danti, V. (1567). Trattato delle perfette proporzioni, en Trattati d'arte, P. Barocchi, Bari, 1960 Gardner, H. (1995). Mentes creativas. España: Ediciones Paidós.

Lapoujade, M. N. (1988). Filosofía de la imaginación. México: Ed. Siglo XXI.

Marina, J. A. (1993). Teoría de la inteligencia creadora. Barcelona: Anagrama.

Martínez Peñaloza, P. (1980). Tres notas sobre el arte popular en México. México: Miguel Ángel Porrúa

Masouka, S. (1994). "The papier-maché art of the Linares family", en Calavera. Catálogo de exposición del Fowler Museum of Cultural History. USA: University of California.

Ovando Shelley, C. (2008) "Las artesanías como artífices culturales de la nación," en La identidad nacional mexicana en las expresiones artísticas. México: UNAM

Platon (1959). La República, México: UNAM

Plotino (1955). Eneada V. Buenos Aires: M. Aguilar Editor

Read, H. (1965). Orígenes de la forma en el arte. Argentina: Proyección. 
Rubert de Ventós, X. (1989). Teoría de la sensibilidad. Barcelona: Península.

Tatarkiewics, W. (1997). Historia de seis ideas arte, belleza, forma, creatividad, mímesis, experiencia estética. Barcelona: Ed. Tecnos

\begin{abstract}
It was economic necessity and the proximity with one of the state of Oaxaca's most important archaeological sites that sparked awareness for the demand for innovative products amongst the men of the town of Arrazola, who were originally farmers. That spark led them to develop a handicraft tradition that has thrived for the past 80 years. The creation and sale of the carved copal-wood pieces made in Arrazola has led the artisans to develop innovative processes that have undergone transformations over time as needs changed.

They taught themselves how to carve, and developed certain shapes over years of isolation, in complete secret, in family workshops in the creators' houses. Ultimately, that led to clear, distinct styles that have been preserved up to this day. However, political and economic crises have recently forced them out of isolation, and they have instead formed organizations aimed at promoting their members' pieces.

The peculiarity of the Arrazola creations is that they nominally correspond to animals in nature but in actual fact, in terms of shape, colour, and composition, they represent a new reality that exists only in the fantasies of their creators' minds. Through the power of their imagination, the creators visualize the animal's form before carving it with a machete and regular kitchen knives and finally decorate it with acrylic paints.

The carvers call themselves artisans, and although some of them feel they are the possessors of an art that is a natural gift that comes from divine inspiration, most of them describe the creative process as a complex combination of mental planning enriched by observation, experimentation, and constant effort aimed at coming up with innovation.
\end{abstract}

Keywords: pioneering- experimental cinema - video art - filmmaking - cultural management - Goethe - technology - new media - feminisms

Resumo: Necessidade econômica combinada com a proximidade de um dos sítios arqueológicos mais importantes do estado de Oaxaca aumentou a consciência sobre a demanda por produtos inovadores Homens população de Arrazola, originalmente camponeses temporários. Isso os levou a desenvolver uma tradição artesanal que floresceu nos últimos 80 anos. Tanto a criação e comercialização de peças esculpidas em madeira copal produzido em Arrazola levou artesãos para criar processos inovadores que foram transformadas ao longo do tempo de acordo com a necessidade.

A partir técnica de auto-aprendizagem de escultura, a evolução das formas de cada artesão foi desenvolvido por anos de isolamento e totalmente secreto em oficinas familiares localizados nas casas de seus criadores alcançar uma definição clara de estilos que são preservados até a data, mas as constantes crises políticas e econômicas forçaram-nos recentemente a deixar esse isolamento para formar organizações civis temáticas cujo objetivo é promover juntos as peças de todos os seus membros. 
A peculiaridade das criações de Arrazola é nominalmente correspondem aos conhecidos mas os animais formais, cromáticas e de composição apresentar uma proposta de uma nova realidade existente apenas na imaginação de seus criadores que-los a visualizar antes do corte através do seu poder imaginativo e elas são materializadas através do uso de madeira, um facão, facas caseiras e tinta acrílica.

Lapidários se definiram como artesãos e embora alguns titulares arte se sentir como um dom natural ligada a inspiração divina, principalmente descrever o processo criativo como uma combinação de planejamento mentais complexas enriquecida pela observação, experimentação e o esforço constante sempre voltado para a busca pela inovação.

Palavras chave: imaginação - inovação - processo criativo

[Las traducciones de los abstracts fueron supervisadas por el autor de cada artículo] 